\title{
Differential binding of Haemophilus influenzae to human tissues by fimbriae
}

\author{
L. M. T. STERK, L. VAN ALPHEN*, L. GEELEN-VAN DEN BROEK, H. J. HOUTHOFF† and \\ J. DANKERT
}

Departments of Medical Microbiology and tPathology, University of Amsterdam, Academic Medical Centre, Meibergdreef 15, NL-1105, AZ Amsterdam, The Netherlands

\begin{abstract}
Summary. The hypothesis was investigated that tissue tropism of Haemophilus influenzae during colonisation and infection is associated with the ability of fimbriate bacteria to bind to the organs and cell types involved. $H$. influenzae type b with fimbriae (strain $770235 f^{+}$) bound to several cell types, including ciliated columnar epithelial cells, pneumocytes, ependymal cells, glial cells, connective tissue fibroblasts, synovial cells, antigen-presenting cells, lymphocytes, erythrocytes and endothelial cells. Binding of $\boldsymbol{H}$. influenzae to kidney, liver and conjunctiva cells was poor. Fimbriae-specific monoclonal antibody (MAb 6HE8) inhibited this binding. Some binding to endothelial cells and macrophages was also observed with non-fimbriate strains. This binding was not inhibited by MAb 6HE8. We conclude that in-vitro binding of fimbriate $H$. influenzae is mainly to those tissues and cells where $H$. influenzae is found during colonisation and infection. The data suggest that a shift to the nonfimbriate form is required for bacteria in the bloodstream to escape clearance mechanisms mediated by blood cells.
\end{abstract}

\section{Introduction}

Haemophilus influenzae is a normal inhabitant of the human nasopharynx and causes various infectious diseases, which are restricted to man. Capsulate strains with a serotype b polysaccharide cause mainly meningitis, epiglottitis, cellulitis, arthritis, pneumonia and sepsis; non-typable $H$. influenzae strains cause nasopharyngitis, pharyngitis, (chronic) bronchitis, otitis media and sinusitis. ${ }^{1}$

Although the capsular polysaccharide of $H$. influenzae type $b$ mainly determines the survival of the bacterium in body fluids, ${ }^{1}$ the mechanisms responsible for tissue tropism of $\boldsymbol{H}$. influenzae are not known. The ability of bacteria to adhere to specific host cells is regarded as a pre-requisite for the onset of infectious diseases. ${ }^{2}$ Adherence may be an important mechanism in determining the organ and tissue specificity during infection. Both capsulate and non-capsulate strains of $H$. influenzae are able to adhere to oropharyngeal epithelial cells. This process is mediated mainly by fimbriae. ${ }^{3-10}$ Fimbriae of various bacterial species recognise different cell receptors, ${ }^{2,11}$ which have often a specific distribution, ${ }^{11-13}$ e.g., Escherichia coli causing neonatal meningitis binds through S-fimbriae to the luminal surfaces of the vascular endothelium and of the epithelium lining the choroid plexuses and brain

Received 25 Sept. 1990; revised version accepted 8 Dec. 1990. *Correspondence should be sent to Dr L. van Alphen. ventricles (ependyma). ${ }^{12}$ The AnWj blood group antigen is the receptor for the fimbriae of $H$. influenzae. ${ }^{13}$ The receptors for the fimbriae on oropharyngeal epithelial cells and erythrocytes have a common genetic basis, but their chemical structures have not been resolved. ${ }^{14}$

To determine the significance of fimbriae-mediated adherence in relation to tissue tropism of $\boldsymbol{H}$. influenzae, we analysed the binding of bacteria of the same $H$. influenzae strain, with and without fimbriae, to various human tissues involved in the pathogenesis of $\boldsymbol{H}$. influenzae disease. For optimal morphological clarity the experiments were performed with sections of fixed tissues. The bacteria were stained by an immunoperoxidase method allowing concomitant observation of the bacteria and the tissue structures. The effect of fixation and pre-treatment of the tissues was analysed by comparison of the binding of $H$. influenzae to adenoid tissue sections with binding to fresh adenoid tissue, which is regarded as an appropriate in-vivo model for studying the first steps of $H$. influenzae infection. $^{15}$

\section{Materials and methods}

\section{Bacteria and growth conditions}

$H$. influenzae type b strain 770235 , isolated from cerebrospinal fluid, was used throughout the study. This strain has been described before $\mathrm{e}^{10,13}$ and was 
originally reported not to express fimbriae. ${ }^{10}$ After seven enrichment cycles by culturing human erythrocytes with attached bacteria, the strain became heavily fimbriated and was able to agglutinate human erythrocytes and to bind strongly to oropharyngeal epithelial cells. ${ }^{10,13,14}$ This fimbriate variant is designated as strain $770235 \mathrm{f}^{+} .{ }^{10}$ The presence of fimbriae on these bacteria was assessed by electronmicroscopy after negative staining with phosphotungstate. Bacteria were cultured overnight on heated blood ("chocolate") agar plates at $37^{\circ} \mathrm{C}$ in a $\mathrm{CO}_{2}$ incubator and then resuspended to a density of $10^{9} \mathrm{cfu} / \mathrm{ml}$ in Dulbecco Modified Eagle Medium (DMEM; Gibco, Breda, The Netherlands) containing fetal calf serum (FCS) $10 \%$, as described before. ${ }^{10,13}$

\section{Fresh adenoid tissue}

Fresh adenoid tissue was obtained by adenectomy from children (1-6 years) with hyperplastic adenoids related to repeated upper respiratory tract infections or otitis media. Adenectomy was decided on clinical indications in infection-free periods. The adenoid tissue was collected in DMEM containing FCS 10\%, washed twice with DMEM and cut into pieces of about $1 \mathrm{~cm}^{3}$. Tissues were discarded if $H$. influenzae was detected immunochemically in sections. Adenoids from five individuals were further processed, as indicated below.

\section{Post-mortem material}

Material taken at autopsy from tissues without disease, or biopsies of human tissues, were selected for examination. Only those specimens were used which were fixed within $5 \mathrm{~h}$ of death and that did not show any macroscopic degeneration.

\section{Preparation of tissue sections}

Pieces of tissue $\left(10 \times 15 \times 3 \mathrm{~mm}^{3}\right)$ were fixed for $1 \mathrm{~h}$ at $22^{\circ} \mathrm{C}$ in formaldehyde $4 \% \mathrm{w} / \mathrm{v}$ buffered with phosphate-buffered saline (PBS) and were dehydrated by subsequent immersion, successively, in $70 \%, 80 \%$, $96 \%$ and $100 \%$ ethanol, each step for $1 \mathrm{~h}$, followed by toluene for $1 \mathrm{~h}$. The dehydrated tissues were embedded in paraffin, unless otherwise specified, and then cut into $3-\mu \mathrm{m}$ sections. The sections were transferred to poly-L-lysine-coated glass slides and were incubated with human plasma protein for $4 \mathrm{~h}$ at $37^{\circ} \mathrm{C}$, to improve adhesion, and stored subsequently if necessary. The sections were deparaffinised in xylol and rehydrated with ethanol-water mixtures.

\section{Preparation of nasopharyngeal epithelial cells}

Freshly obtained oropharyngeal epithelial cells from a healthy adult $\left(10^{5} / \mathrm{ml}\right)$ were incubated for $1 \mathrm{~h}$ at room temperature either with PBS or - in the same way as tissue sections - with formaldehyde, ethanol- water, toluene, xylol, pepsin in $\mathrm{HCl}$ (see ahead), or $\mathrm{HCl}$ alone, followed by triple washing with PBS as previously described. ${ }^{10}$

\section{Adherence of bacteria to fresh adenoid tissue}

Pieces of tissue were immersed in $2 \mathrm{ml}$ of DMEM containing FCS $10 \%$ and $2 \times 10^{5} \mathrm{cfu}$ of bacteria and incubated for $30 \mathrm{~min}$ at $37^{\circ} \mathrm{C}$ in a waterbath and subsequently in a $\mathrm{CO}_{2}$ incubator for various lengths of time. Binding-inhibition experiments with monoclonal antibodies (MAbs) were performed to analyse the role of fimbriae in the binding of $H$. influenzae to these cells. An $H$. influenzae suspension of $2 \times 10^{5} \mathrm{cfu} /$ $\mathrm{ml}$ was pre-incubated for $30 \mathrm{~min}$ at $37^{\circ} \mathrm{C}$ with an equal volume of culture supernate from murine hybridoma cell line $6 \mathrm{HE} 8$, which produces anti-fimbriae antibodies. ${ }^{10}$ The pre-incubated bacteria were incubated with the tissue sections in the same way as for fresh bacterial suspensions. MAb 7BB1, specific for a heterologous LPS of $H$. influenzae type b (LPS-10), was used as a control. ${ }^{10,16}$ The two MAbs did not agglutinate the bacteria, nor did they bind to the Fc receptor on the tissue cells. ${ }^{10}$ After incubation, the tissue was rinsed five times with PBS, fixed with formaldehyde $4 \%$, and sections were cut.

\section{Adherence of bacteria to tissue sections}

Immediately after deparaffination, the sections were pre-incubated for $15 \mathrm{~min}$ at $37^{\circ} \mathrm{C}$ with pepsin $0.5 \%$ in diluted $\mathrm{HCl}, \mathrm{pH} 2 \cdot 0$, and then with normal swine serum $10 \%$ for $15 \mathrm{~min}$ at $22^{\circ} \mathrm{C}$ to reduce non-specific binding (see Results). Pre-incubated sections were overlaid with bacterial suspensions, prepared as described above $\left(10^{9} \mathrm{cfu} / \mathrm{ml}\right)$, incubated for $1 \mathrm{~h}$ in a humid atmosphere at $37^{\circ} \mathrm{C}$ and washed three times with PBS containing Tween-20 0.05\%. The fimbriaedependence of the binding of $\boldsymbol{H}$. influenzae to tissue sections was analysed in inhibition experiments with MAbs $6 \mathrm{HE} 8$ and 7BB1, as described for fresh adenoid tissue.

\section{Adherence of bacteria to oropharyngeal epithelial cells}

Glass slide smears of oropharyngeal epithelial cells, ${ }^{13}$ either untreated or treated (as above) with formaldehyde, ethanol-water mixtures, toluene, xylol, pepsin in $\mathrm{HCl}$, or $\mathrm{HCl}$ alone, were incubated with bacterial suspensions in the same way as the tissue sections.

\section{Staining of bacteria in tissue sections}

Incubated tissue sections were stained immunochemically with MAbs to detect specifically $H$. influenzae. In this procedure, the sections were incubated for $1 \mathrm{~h}$ at room temperature with murine ascites fluid (diluted 1 in 500 in PBS) raised with hybridoma 
cell lines producing MAbs directed, respectively, to outer-membrane protein P6 (MAb 8BD9), outermembrane protein a (MAb 5HA5) and LPS (MAb 3DA11). The production and specificity of these MAbs have been described before. ${ }^{10}$ The sections were rinsed with PBS for $5 \mathrm{~min}$ and incubated for $20 \mathrm{~min}$ with $\mathrm{H}_{2} \mathrm{O}_{2} \quad 0.03 \%$ in methanol at $4^{\circ} \mathrm{C}$ to reduce endogenous peroxidase activity. After another wash with PBS, rabbit anti-mouse immunoglobulin coupled to horse-radish peroxidase (Dako, Copenhagen, Denmark) was added at a dilution of 1 in 50 in PBS with pooled human serum $10 \% \mathrm{v} / \mathrm{v}$, and the slides were incubated for $30 \mathrm{~min}$ at room temperature. The staining was amplified by a subsequent incubation with swine anti-rabbit serum coupled to horse-radish peroxidase (Dako), diluted 1 in 100 in PBS with human pooled serum, for $30 \mathrm{~min}$. After washing with PBS, sections were stained with diaminobenzidine $0.5 \%$ in $0.05 \mathrm{M}$ Tris- $\mathrm{HCl}, \mathrm{pH} 7.6$, containing $\mathrm{H}_{2} \mathrm{O}_{2}$ $0.03 \%$. The reaction was allowed to proceed for $15 \mathrm{~min}$ and was then stopped by washing with distilled water.

Sections that were not incubated with bacteria were included as controls in all series to allow assessment of the tissue morphology and detection of background staining. Bacterial suspensions fixed to glass slides with methanol for $5 \mathrm{~min}$ were included as positive controls for the staining procedures. Cells were counterstained with haematoxylin and the sections were examined by light microscopy.

\section{Results}

\section{Binding of $H$. influenzae to fresh adenoid tissue}

After incubation of fresh adenoids with the fimbriate $H$. influenzae strain $770235 \mathrm{f}^{+}$, followed by fixation, paraffin embedding and sectioning, immunocytochemically stained rods were observed on columnar epithelial cells and their cilia, in the epithelial cell layer and under the epithelial cells near lymphocytes and macrophages, and in vessels (figs. 1A, B). We observed small differences in the degree of binding between adenoid tissues from different donors. These differences, in the numbers of stained particles, were only quantitative and were within the binding categories indicated in table I. Binding of fimbriate bacteria was inhibited by the anti-fimbriae MAb 6HE8 and not by MAb 7BB1 specific for LPS, except for binding to endothelium, macrophages and fibroblasts. Binding inhibited specifically by MAb $6 \mathrm{HE} 8$ has been shown to be fimbriae-specific. ${ }^{3,5,7,13}$ Nonfimbriate bacteria did not bind to cells of fresh adenoid tissue. These data show that $H$. influenzae with fimbriae binds to some cell types of adenoid tissue before

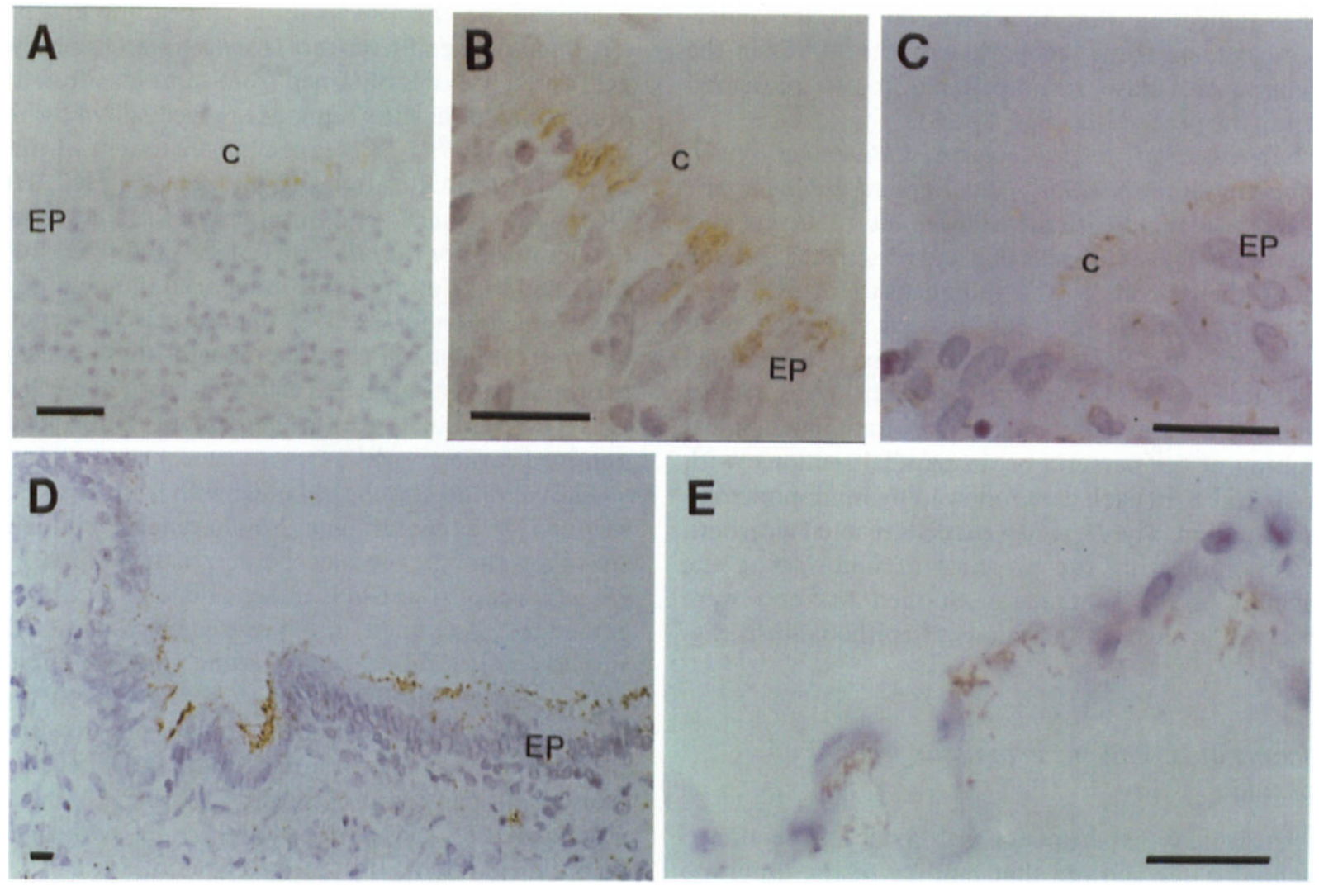

Fig. 1. Comparison of adherence of fimbriate $H$. influenzae strain $770235 \mathrm{f}^{+}$to fresh adenoids with that obtained with sections of various tissues of the air passages of the lower respiratory tract. A, B, strong adherence when incubated with fresh adenoid followed by fixation, embedding and sectioning; $\mathbf{C}$, strong adherence when incubated with paraffin sections of fixed adenoid; strong adherence to tissue sections of, $\mathbf{D}$, bronchus and, $\mathbf{E}$, alveoli incubated with the same fimbriate bacteria (EP, epithelium; C, ciliated cells). The bacteria were immunostained after incubation with a mixture of MAbs 8BD9, 5HA5 and 3DA11, except in B. The bacteria in B were incubated with MAb 6HE8 (anti-fimbriae). Bar, 0.01 mm. 
Table I. Effect of MAbs on the adherence of $H$. influenzae strain $770235 \mathrm{f}^{+}$to paraffin-embedded sections of human tissue

\begin{tabular}{|c|c|c|c|}
\hline \multirow{3}{*}{$\begin{array}{l}\text { Tissue from } \\
\text { (organ) }\end{array}$} & \multicolumn{3}{|c|}{ Degree of binding } \\
\hline & \multirow{2}{*}{ untreated } & \multicolumn{2}{|c|}{ in the presence of $\mathrm{MAb}$} \\
\hline & & $6 \mathrm{HE} 8$ & 7BB1 \\
\hline Cerebrum & ++ & - & ++ \\
\hline Upper respiratory tract & ++ & - & ++ \\
\hline Lung & ++ & - & ++ \\
\hline Joint & + & - & + \\
\hline Eye & - & ND & ND \\
\hline Spleen & ++ & - & ++ \\
\hline Lymph node & ++ & - & ++ \\
\hline Liver & - & - & + \\
\hline Kidney & - & - & - \\
\hline Blood vessels & ++ & - & ++ \\
\hline Connective tissue & ++ & - & ++ \\
\hline
\end{tabular}

++ , Strong to abundant binding (most of the cells bound several bacteria); + , sparse but significant binding (bacteria were seen on at least $10 \%$ of the cells); - , no binding (bacteria were rarely found on these cells). Representative examples are shown in the figs.

penetration into the tissue. Bacteria without fimbriae did not interact with adenoid cells. Fixation and embedding after incubation of fresh tissue with bacteria did not result in disappearance of stained rods, indicating that the bacteria and the outermembrane antigens recognised by the MAbs in the immunoperoxidase test appeared to be preserved during the procedures (figs. 1A, B).

Expression of fimbriae during interaction of $\boldsymbol{H}$. influenzae strain $770235 f^{+}$with fresh adenoid. The use of fresh adenoidal tissue allowed us to investigate whether $\boldsymbol{H}$. influenzae cells that had penetrated through the epithelial cells to the submucosa still expressed fimbriae. Sections of fresh tissue which had been incubated with bacteria, and then fixed, embedded and sliced, were incubated either with MAbs against outer-membrane components for immunochemical staining of the bacteria or, in parallel sections, with MAb 6HE8, in each case followed by immunoperoxidase staining. The $H$. influenzae cells reacted with both MAbs, indicating the presence of fimbriae on the bacteria in the submucosa. Stained bacteria were observed in the tight junctions of epithelial cells (fig. 1B).

\section{Binding of $H$. influenzae to tissue sections of adenoid}

Preliminary experiments with fixed and sectioned adenoid tissue showed that binding of the fimbriate $H$. influenzae strain $770235 \mathrm{f}^{+}$and its non-fimbriate variant strain 770235 varied extensively with most cell types of adenoid tissue. This binding was hardly diminished in the presence of MAb 6HE8, which is specific for the fimbriae, indicating that the majority of the binding was not fimbriae-dependent and was most likely a non-specific interaction (sticking of bacteria). Enrichment of the incubation medium with Triton-X 100 1\%, Tween-20 1\%, FCS 10\%, or bovine milk powder (ELK ; Campina, Eindhoven, The Netherlands) $1 \%$ which prevent non-specific binding, resulted in a slight reduction in the overall binding. Pre-incubation of the adenoid tissue sections with pepsin, after adjustment of the $\mathrm{pH}$ to $2 \cdot 0$ by addition of $\mathrm{HCl}$ (the $\mathrm{pH}$ at which the enzyme is active), but not pre-incubation with $\mathrm{HCl}$ alone, resulted in a strong reduction of the binding of $H$. influenzae without fimbriae to most of the cell types tested. Binding to endothelium, fibroblasts in connective tissue and tissue macrophages did not disappear after such pretreatment (fig. 1C). Specific binding of fimbriate bacteria (i.e., binding which could be inhibited by MAb 6HE8 but not by MAb 7BB1) was noted, after such pre-treatment, to the same cells as those to which fimbriate $H$. influenzae bound in fresh adenoid tissue (figs. 2B, C, D and table I). The viability of the bacteria, as determined by the numbers of $\mathrm{cfu}$, was not affected by any of these pre-treatments.

\section{Binding of $H$. influenzae to oropharyngeal epithelial cells}

Since a rather harsh treatment of the tissue sections was required to avoid non-specific binding, we examined the effect of fixation, embedding and pretreatmenton the adherenceof $H$. influenzae. Oropharyngeal epithelial cells obtained from scrapings from the oropharynx of healthy humans are well-suited for this purpose. ${ }^{3-7,9,10,13,14}$ Neither pre-treatment of these cells with formalin, followed by pepsin $+\mathrm{HCl}, \mathrm{HCl}$ $\mathrm{HCl}$ alone, toluene, xylol or ethanol, for $1 \mathrm{~h}$ at room temperature, nor the effect of Triton-X100, Tween-20, ELK and FCS, appreciably influenced the binding of $H$. influenzae strain $770235 \mathrm{f}^{+}$to these cells. The effects of pre-treatments on the adherence of these bacteria to oropharyngeal epithelial cells are shown in fig. 3(AG). These results are in agreement with results obtained earlier. ${ }^{10,13,14}$

The combined results obtained with fresh adenoids, sections of adenoids, and oropharyngeal epithelial cells show that the binding characteristics of fimbriate $\boldsymbol{H}$. influenzae to unfixed, intact adenoids and fixed, embedded, sectioned and pre-treated tissues were similar, indicating that the binding sites specific for $H$. influenzae with fimbriae were not inactivated during the fixation, embedding and pre-treatment steps. Subsequently, we pre-incubated all tissue sections with pepsin and included Tween-20 in the washing buffers, as described in Materials and methods, before they were incubated with bacteria.

\section{Binding of bacteria to tissue sections of various organs}

A major difference was observed between the binding of $H$. influenzae strain $770235 \mathrm{f}^{+}$and that of 

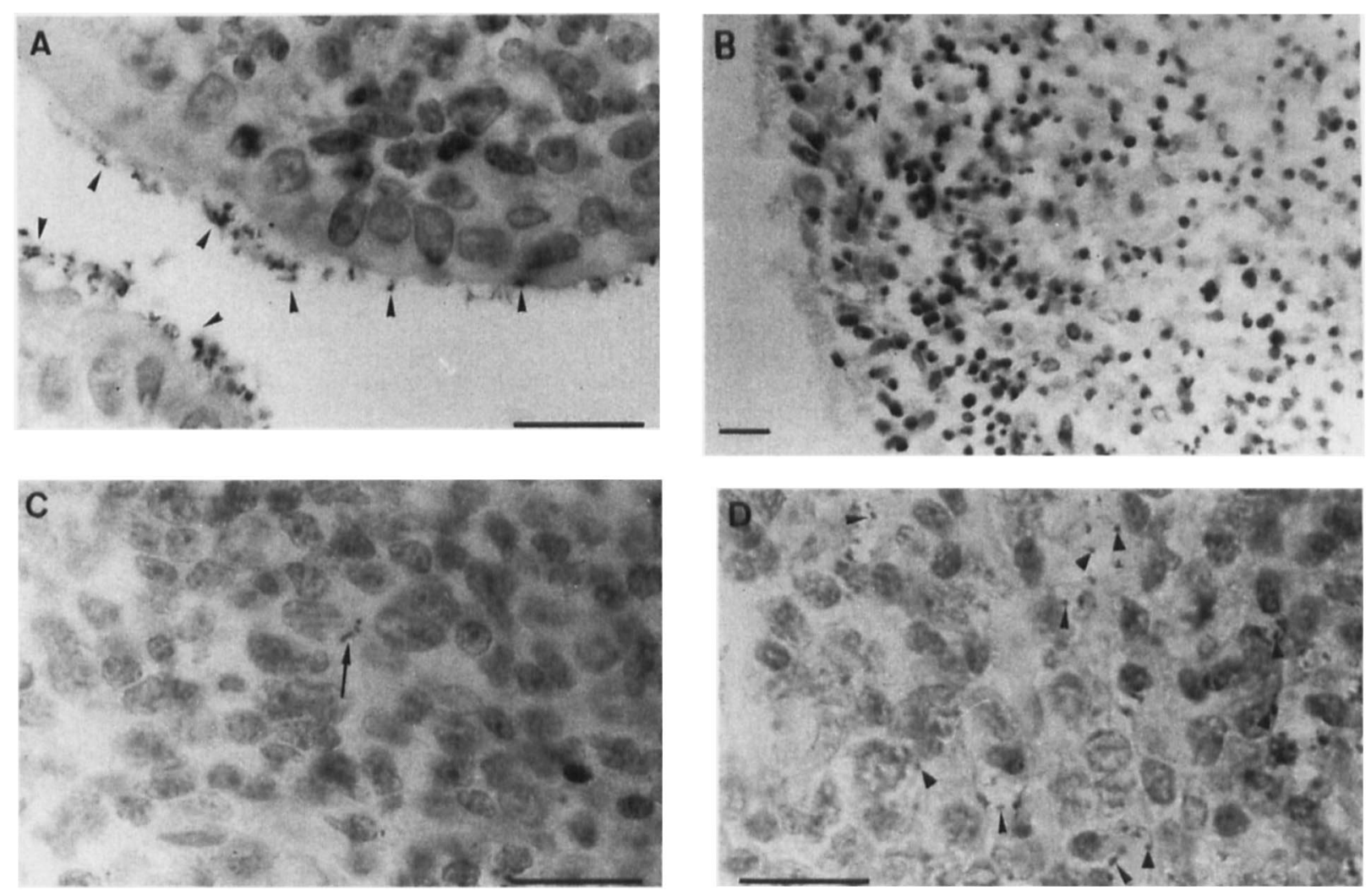

Fig. 2. Adherence of $H$. influenzae strain $770235 \mathrm{f}^{+}$to paraffin-embedded sections of adenoid. A, abundant adherence to epithelium, especially the ciliated cells; B, no adherence after pre-incubation of the bacteria with fimbriae-specific MAb 6HE8; C, sparse binding to lymphoid tissue after inhibition with MAb 6HE8; in contrast to, D, strong binding with control MAb 7BB1, which did not inhibit binding. Bar, $20 \mu \mathrm{m}$. Bacteria were stained as in fig. 1 .

strain 770235 to various tissues. These results are summarised in tables I and II. H. influenzae strain 770235 (without fimbriae) was found only on vascular endothelial cells, especially of the capillaries (fig. 4A), and on macrophages from various sites of the human body. This binding was not inhibited by anti-fimbriae MAb 6HE8. Fimbriae-specific binding of $H$. influenzae strain $770235 \mathrm{f}^{+}$(i.e., binding which was inhibited by MAb 6HE8 but not by MAb 7BB1) was clearly observed in sections of brain, lung, joints (especially the synovial membrane), adenoid and other pharyngeal tissues, but only weakly in those of liver, kidney and the eye (table I). However, the various cell types in these tissues showed different degrees of binding (table II).

In the brain, binding was predominantly to glial cells (astrocytes and oligodendrocytes) and to the connective tissue surrounding the blood vessels, especially those of the large sinuses. Many bacteria were seen on ependyma of the choroid plexus and on the ciliated ependyma of the ventricles. The bacteria were seen on both sides-ventricular and stromal (fig. 5).

In the lower respiratory tract, fimbriate bacteria were found in similar numbers on alveolar macrophages, type II pneumocytes and in the bronchi on epithelial cells, especially the ciliated ones (fig. 1D, E). In the upper respiratory tract, binding to the epithelial cells was observed in the same way as described for the bronchi and adenoids, and also to the fibroblasts in the subepithelial connective tissue. The normal respiratory tract is lined by pseudostratified ciliated columnar, cuboidal, and squamous epithelial cells. Strain $770235 \mathrm{f}^{+}$bound only to the ciliated columnar cells and hardly at all to the cuboidal or squamous epithelial cells. Bacteria appeared to be trapped in the respiratory mucus when this was present on the epithelial cell layer. This was seen most clearly in cryosections of fresh adenoid, in which many $H$. influenzae cells were seen in the slimy mucus material on the surface of the ciliated and squamous epithelium.

In the knee joint, fimbriate bacteria were found in association with synovial cells and on the fibroblasts of the underlying connective tissue. Bacteria were found on the cartilage of the joint only if the surface was damaged. Binding of fimbriate bacteria to connective tissue appeared to be a general phenomenon, since this was also observed with connective tissue in the respiratory tract and the connective tissue surrounding the vena saphena magna and the cerebral vessels.

The binding of $H$. influenzae to the lymphoid tissues of adenoid, spleen and lymph nodes showed marked similarities. Bacteria with fimbriae were found on monocytes, macrophages, follicle centre cells, dendrit- 

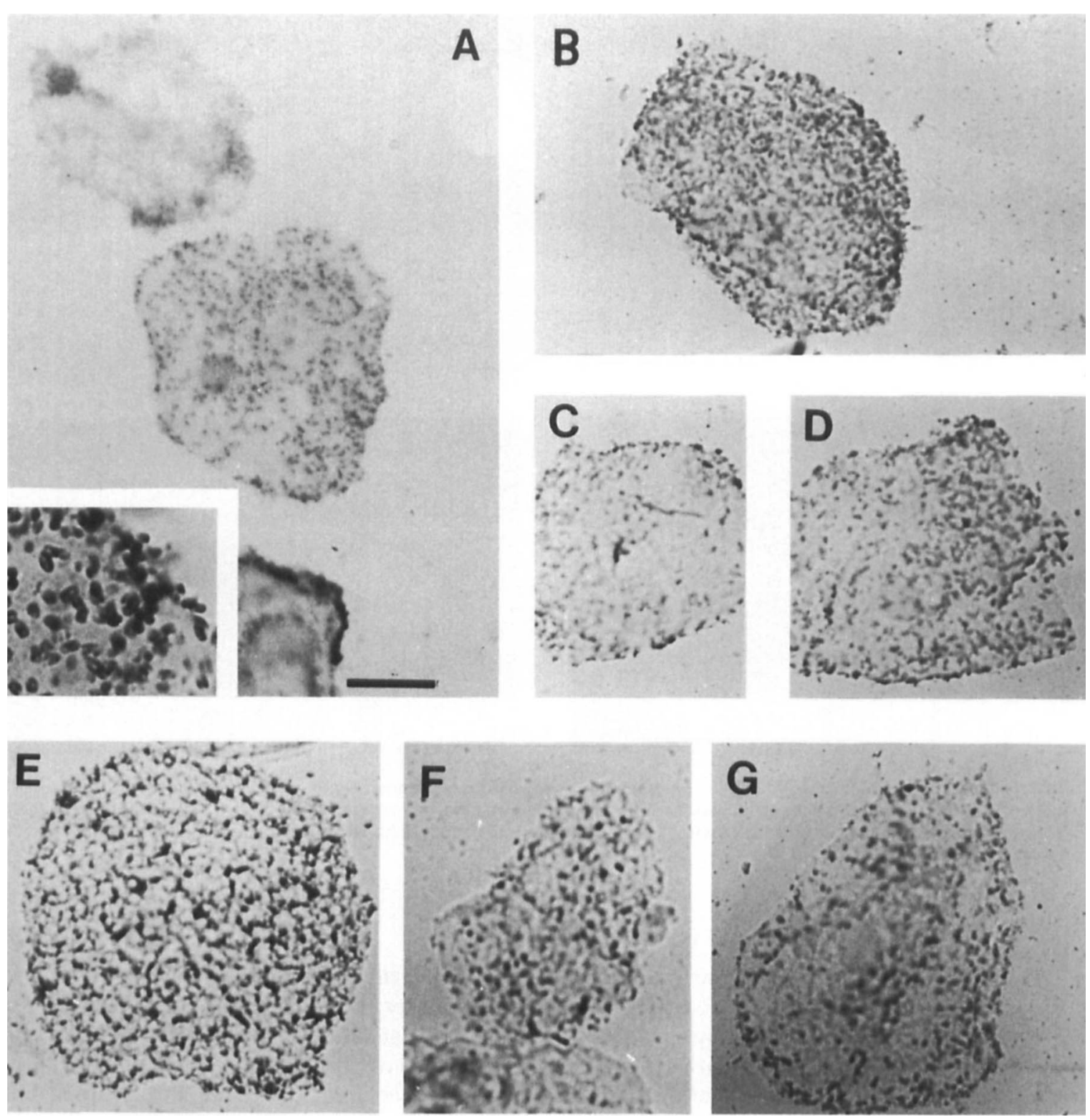

Fig. 3. Effect of various pretreatments of oropharyngeal epithelial cells on the adherence of $H$. influenzae strain $770235 \mathrm{f}^{+}$to these cells. A, methanol-fixed oropharyngeal epithelial cells obtained from scrapings; note that the bacteria did not bind to all cells. A four-fold enlargement of part of an epithelial cell with bacteria is shown in the insert to show the bacterial morphology. B-G, adherence to oropharyngeal epithelial cells pretreated with various agents: B, formalin; C, ethanol 70\%; D, toluene; E, xylol; F, pepsin- $\mathrm{HCl}$; and $\mathbf{G}, \mathrm{HCl}$ alone. Bar, $20 \mu \mathrm{m} ;$ all have the same enlargement. EP, epithelium; M, surrounding medium.

ic reticulum cells and lymphocytes. Only the binding to macrophages was not inhibited by anti-fimbrial antibodies.

The liver and kidney, both used as control organs, bound $H$. influenzae very poorly. In the liver, some bacteria were found, after incubation with $H$. influenzae strain $770235 \mathrm{f}^{+}$, in sinusoidal blood vessels, probably attached to endothelium. In the kidney, bacteria were bound to the endothelium of the glomeruli and in very small numbers to the mesangium and the luminal site of the tubuli.

Binding of the fimbriate bacteria to erythrocytes was always seen, wherever these cells were found (fig. 4B). This is consistent with the known ability of these bacteria to cause haemagglutination by the bloodgroup $\mathrm{AnWj}$ antigen. ${ }^{14}$

\section{Discussion}

The experiments described here were designed to test the hypothesis that tissue tropism of $H$. influenzae during colonisation and infection is determined by the presence of specific binding sites for the fimbriae of these bacteria. Tissue sections were incubated with bacteria, followed by immunochemical labelling of the bacteria with immunoperoxidase reagents and examination by light microscopy. Compared with immunofluorescence, this technique has the advantage that it permits the simultaneous visualisation of bacteria and cells, which is important for the identification of the binding sites in the tissues.

The ability of fimbriate $H$. influenzae to bind to various cells differed from those of the same strain 
Table II. Binding of $H$. influenzae, with and without fimbriae, to various cell types

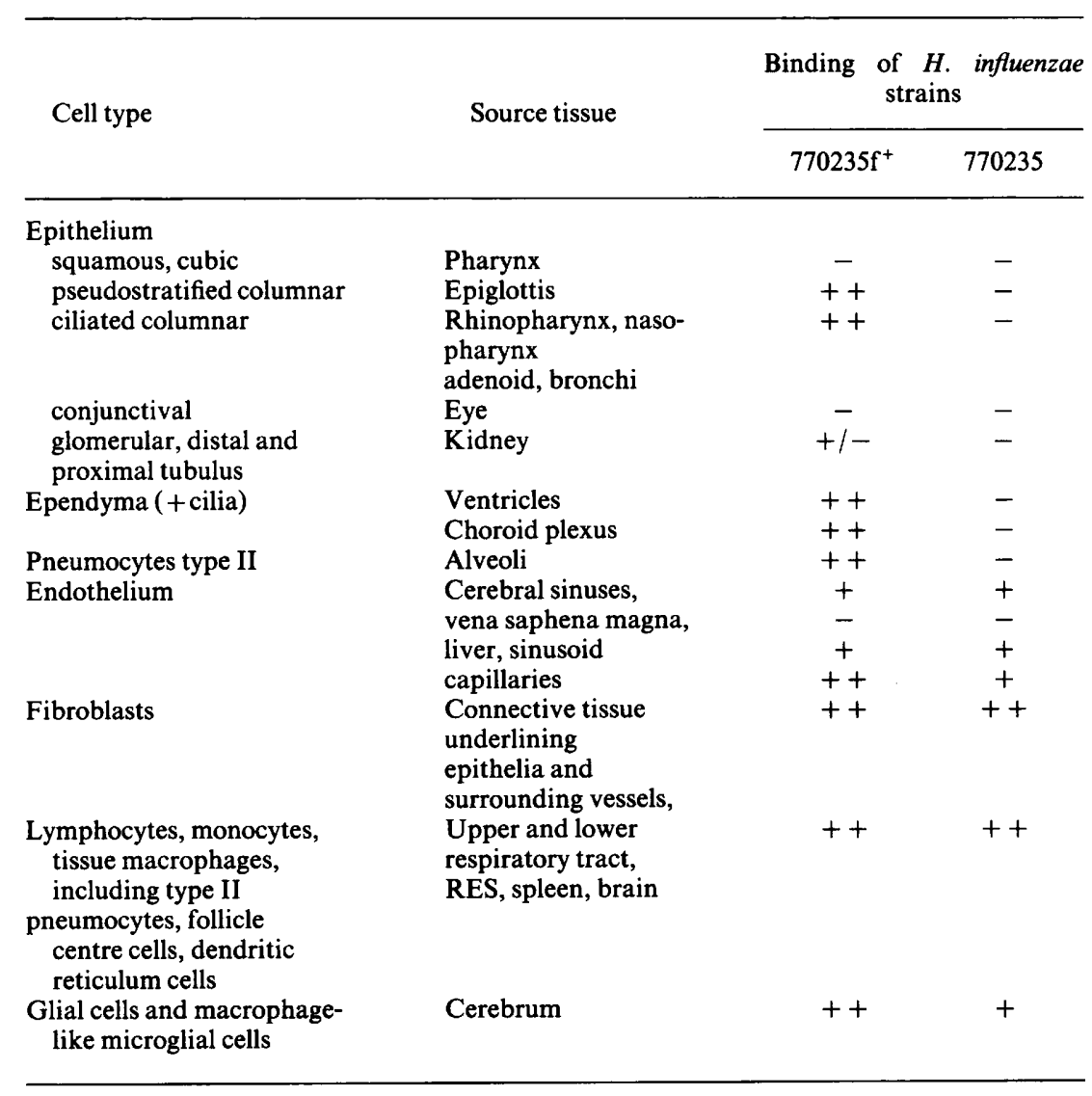

,,+++- , see table I.

without fimbriae. The best way to show specificity of binding is by inhibition experiments with isolated receptor structures or by specific antibodies. However, the receptor for fimbriate and non-fimbriate $H$. influenzae is not known. MAbs specifically inhibiting fimbriae-mediated adherence were included in this study, but nothing is known about the bacterial and host components involved in fimbriae-independent binding. Therefore it is not at present possible to draw conclusions about the specificity of the fimbriaeindependent binding.

The fimbriae appeared to be involved in most of the binding of fimbriate $H$. influenzae to some organs and specialised tissues (tables I and II), since most of the binding was inhibited by MAbs specific for the fimbriae. The residual binding was also seen with nonfimbriate bacteria. Fimbriae-mediated binding was not affected by treatment of the tissues with toluene and pepsin, indicating that the receptor for the fimbriae on the various cell types is probably not a lipid or a protein. This is in agreement with earlier results which suggested that the receptor is probably part of the sugar chain of a glycolipid or a glycoprotein. ${ }^{13}$ The tissues involved in fimbriae-dependent binding include the pharynx, the site colonised by $H$. influenzae in the carrier state, and also organs and tissues involved in respiratory tract infections (rhinopharynx, nasopharynx, bronchi and alveoli). Binding was predominantly to ciliated columnar epithelial cells, to the connective tissue underlying the epithelia and surrounding vessels, and to cells of the immune system. In this respect it is important to note that $\boldsymbol{H}$. influenzae has been found in the epithelium and the subepithelial tissues of the bronchi in patients with chronic bronchitis ${ }^{17}$ and that the bacteria have been shown to penetrate cultured human adenoid tissue in a similar fashion. ${ }^{15}$ Binding to ciliated epithelium was not observed by Farley et al. or Loeb et al ${ }^{8,15}$ Trapping of the bacteria between the cilia is unlikely, since these authors showed that this binding was inhibited specifically by MAbs to the fimbriae and since this type of binding was not observed with non-fimbriate bacteria. We observed also that the bacteria were trapped in the mucus layer overlying the epithelial cells, a common observations in sputum preparations taken during respiratory tract infections. The binding of $H$. influenzae to mucus and connective tissue was striking. Both these materials are rich in glucosaminoglycans. It would be interesting to see whether the receptor for the fimbriae is part of such molecules. Other explanations for the differences in the observed binding to ciliated cells may lie in the differences in methodology used in the previously published studies $^{8,15}$ and in our current studies for the analysis of the interaction between bacteria and cells.

Tissues that are involved in generalised infections 

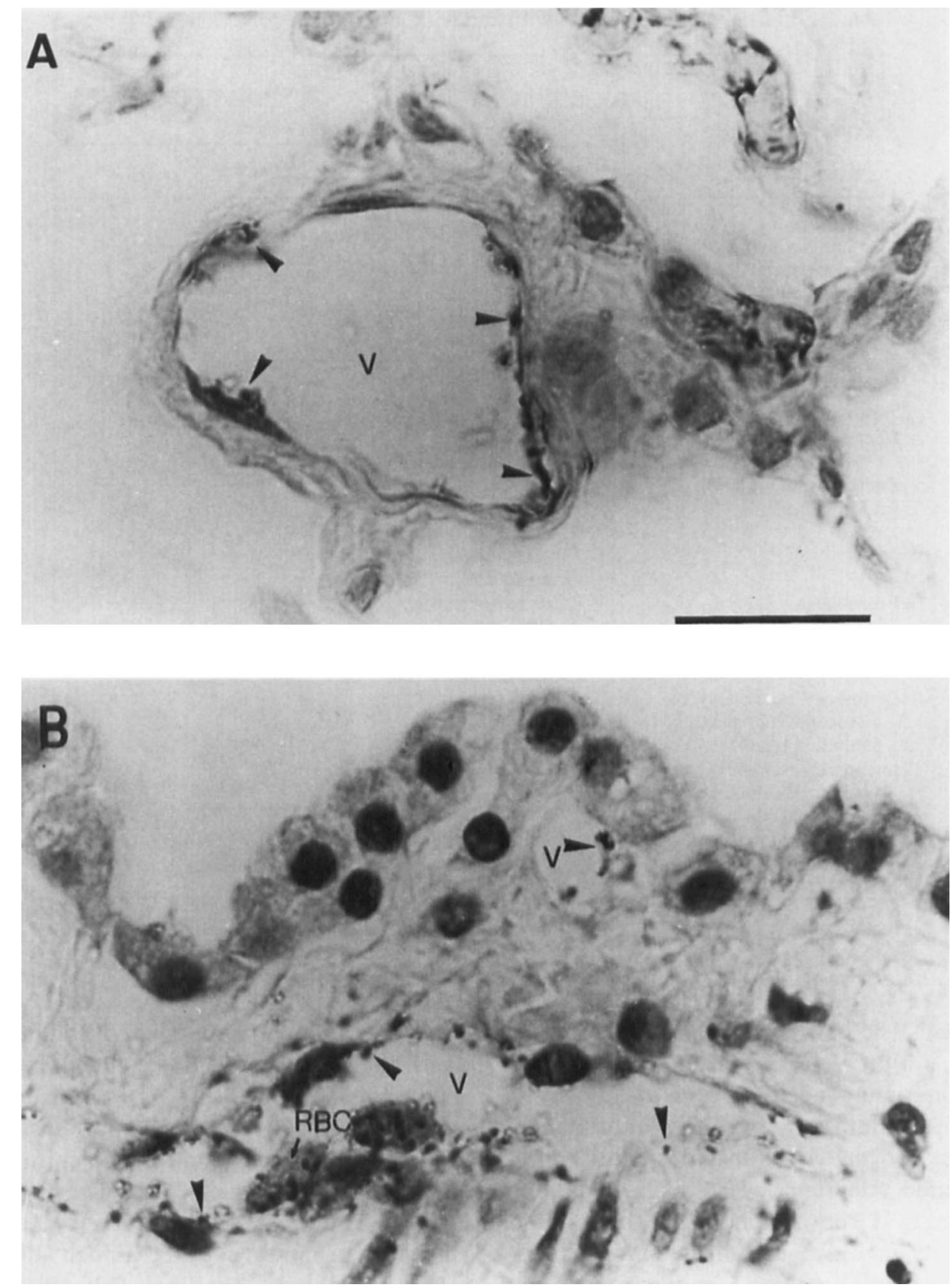

Fig. 4. Adherence of $\boldsymbol{H}$. influenzae to blood vessels. A, strong adherence of $\boldsymbol{H}$. influenzae strain 770235 to the endothelium of a blood vessel in the lung; B, strong adherence of strain $770235 \mathrm{f}^{+}$to a small blood vessel in the brain, in which the bacteria are found on erythrocytes. Bar, $20 \mu \mathrm{m}$. V, blood vessel; RBC, red blood cell. Arrows indicate some of the bacteria adhering to the vessel walls and erythrocytes.

of $H$. influenzae appeared to contain binding sites for fimbriate $H$. influenzae. These included the ependyma of the choroid plexus and the ventricles, on the stromal and ventricular side during meningitis. It is probable that bacteria pass close to these cells when they enter the cerebrospinal fluid from the bloodstream. Binding to the stroma of the cerebrum may indicate that the encephalitis which is sometimes observed after meningitis is also associated with the presence of fimbriae. Similar binding characteristics were found by Parkkinen et al. ${ }^{12}$ for $E$. coli from neonatal meningitis which express mainly S-fimbriae, which recognise terminal neuraminyl 2-3 galactosides as receptor. ${ }^{18}$ Epiglottitis may be explained as an inflammation following binding by fimbriate bacteria, since the bacteria bound to the epithelial cells and the underlying tissue. , $^{4,6}$

The binding of fimbriate bacteria to macrophages, lymphocytes and monocytes suggests that bacteria with fimbriae are recognised by cells of the immune system, thereby probably stimulating clearance of the bacteria. In this case, a non-fimbriate phase may be an advantage for the bacteria which penetrate via the bloodstream into target organs. Fresh isolates from blood cultures are, indeed, much less fimbriate than, for example, strains from the throat or sputum. ${ }^{4,7}$ Based on this clearance mechanism, the survival out of an intranasal inoculum of $10^{5}$ bacteria of one 

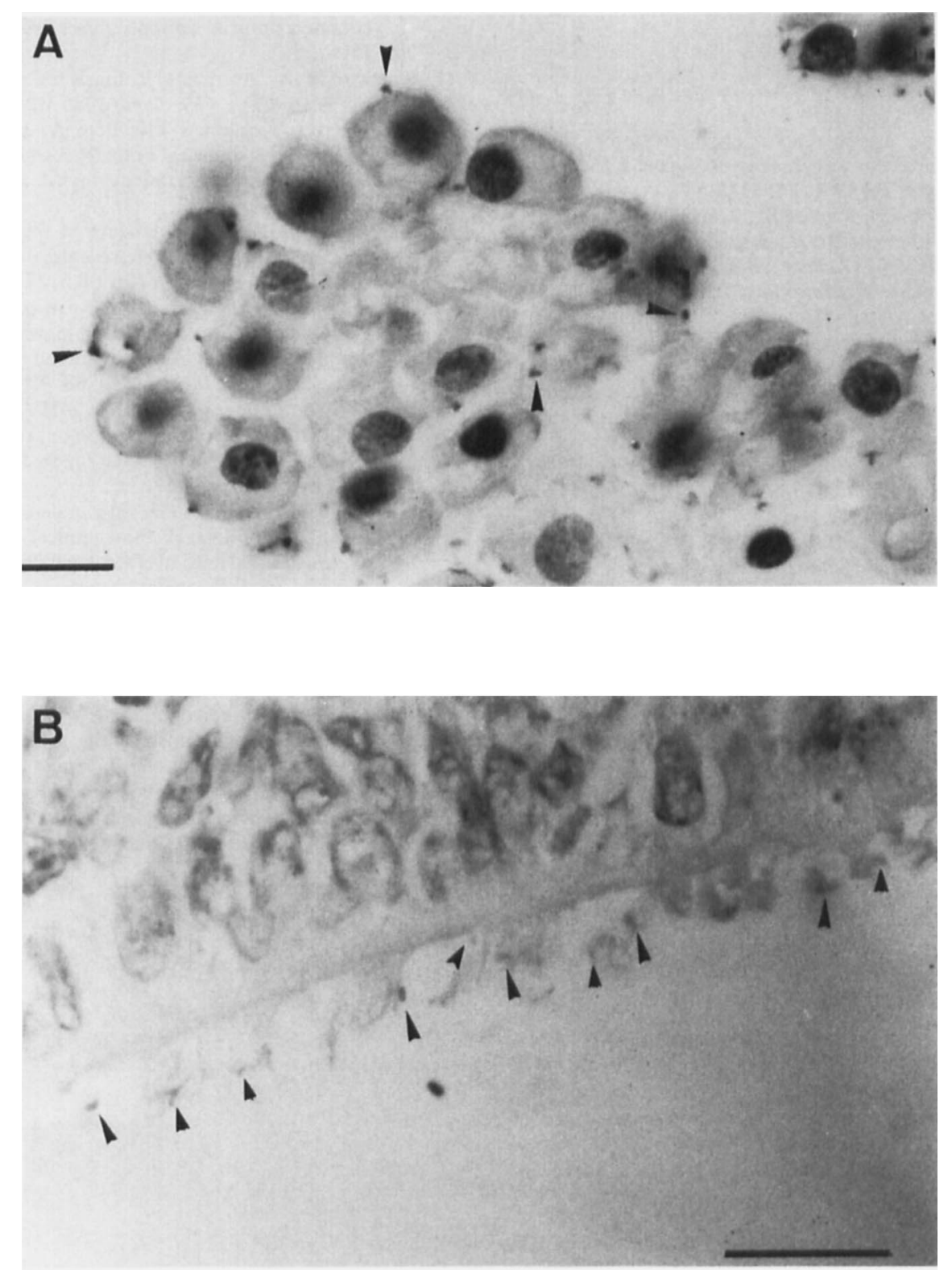

Fig. 5. Adherence of fimbriate $H$. influenzae to brain sections. A, strong adherence of $H$. influenzae strain $770235 \mathrm{f}^{+}$to brain ependyma cells of the choroid plexus; B, strong adherence to the ventricles. Bar, $20 \mu \mathrm{m}$. Some bacteria are indicated by arrows.

organism in the blood stream in an animal model for invasive $H$. influenzae disease ${ }^{19}$ may reflect the natural rate of one non-fimbriate bacterium to $c .10^{5}$ fimbriate cells. Subsequent phase variation to the fimbriate form should be assumed, if adherence to the blood brain barrier is essential for penetration of the bacteria into the cerebrospinal fluid. Whether bacteria which attach to the walls of blood vessels or the spinal cord during infection are fimbriate is not known.

In conclusion, our experiments indicate that fimbriate $H$. influenzae cells have the ability to interact with the surface epithelium and with some cells in various tissues where $H$. influenzae is found during colonisation and infection. Furthermore, fimbriae could be detected on bacteria after penetration of $\boldsymbol{H}$. influenzae to below the epithelial cell layer of fresh adenoid tissue (fig. 1B). These results suggest that fimbriae are a pre-requisite for the tissue tropism of the organism. The absence of fimbriate bacteria on the blood cells in the vessels of fresh adenoid and the direct binding of fimbriate bacteria to these cells in tissue sections fit well with the notion that this type of binding probably contributes to the clearance of bacteria from the circulation. Consequently, phase variation in the expression of fimbriae may be an important mechanism for the bacteria to direct themselves to those cells that they can colonise.

Identification and localisation of the receptor molecules for the fimbriae on these tissues in health and disease may contribute to a better understanding of the pathogenetic mechanisms of $H$. influenzae infections.

We are grateful to Dr $\mathrm{N}$. Walford for reading the manuscript critically and for correcting the English. The skilled photographic assistance of W. Herschbach is very much appreciated. 


\section{References}

1. Turk DC. The pathogenicity of Haemophilus influenzae. J Med Microbiol 1984; 18: 1-16.

2. Beachey EH. Bacterial adherence: adhesion-receptor interactions mediating the attachment of bacteria to mucosal surfaces. J Infect Dis 1981 ; 143: 325-345.

3. Lampe RM, Mason EO, Kaplan SL, Umstead CL, Yow MD, Feigin RD. Adherence of Haemophilus influenzae to buccal epithelial cells. Infect Immun 1982; 35: 166-172.

4. Mason EO, Kaplan SL, Wiedermann BL, Norrod EP, Stenback WA. Frequency and properties of naturally occurring adherent piliated strains of Haemophilus influenzae type b. Infect Immun 1985; 49: 98-103.

5. Pichichero ME. Adherence of Haemophilus influenzae to human buccal and pharyngeal epithelial cells: relationship to piliation. J Med Microbiol 1984; 18 : 107-116.

6. Pichichero ME, Loeb M, Anderson P, Smith DH. Do pili play a role in pathogenicity of Haemophilus influenzae type b? Lancet $1982 ; 2: 960-962$

7. Sable NS, Connor EM, Hall CB, Loeb MR. Variable adherence of fimbriated Haemophilus influenzae type b to human cells. Infect Immun 1985; 48: 119-123.

8. Loeb MR, Connor E, Penney D. A comparison of the adherence of fimbriated and nonfimbriated Haemophilus influenzae type $b$ to human adenoids in organ culture. Infect Immun $1988 ; 56: 484-489$

9. Stull TL, Mendelman PM, Haas JE, Schoenborn MA, Mack $\mathrm{KD}$, Smith AL. Characterization of Haemophilus influenzae type b fimbriae. Infect Immun 1984; 46: 787-796.

10. Van Alphen L, van den Berghe N, Geelen-van den Broek L. Interaction of Haemophilus influenzae with human erythrocytes and oropharyngeal epithelial cells is mediated by a common fimbrial epitope. Infect Immun 1988; 56: 18001806.

11. Karlsson K-A. Animal glycolipids as attachment sites for microbes. Chem Phys Lipids 1986; 42: 153-172.

12. Parkkinen J, Korhonen TK, Pere A, Hacker J, Soinila S Binding sites in the rat brain for Escherichia coli $\mathrm{S}$ fimbriae associated with neonatal meningitis. J Clin Invest 1988; 81 : 860-865.

13. Van Alphen L, Poole J, Overbeeke M. The Anton blood group antigen is the erythrocyte receptor for Haemophilus influenzae. FEMS Microbiol Lett 1986; 37 : 69-71.

14. Van Alphen L, Levene C, Geelen-van den Broek L, Poole J, Bennett M, Dankert J. Combined inheritance of the epithelial cell and erythrocyte receptors for Haemophilus influenzae. Infect Immun 1990; 58: 3807-3809.

15. Farley MM, Stephens DS, Mulks MH et al. Pathogenesis of $\operatorname{IgA} A_{1}$ protease-producing and -nonproducing Haemophilus influenzae in human nasopharyngeal organ cultures. J Infect Dis 1986; 154: 752-759.

16. Van Alphen L, Klein M, Geelen-van den Broek L, Riemens T, Eijk P, Kamerling JP. Biochemical characterization and worldwide distribution of serologically distinct lipopolysaccharides of Haemophilus influenzae type b. J Infect Dis $1990 ; 162$ : 659-663.

17. Hers JFP, Mulder J. The mucosal epithelium of the respiratory tract in muco-purulent bronchitis caused by Haemophilus influenzae. J Pathol Bacteriol 1953; 66: 103-108.

18. Parkkinen J, Finne J, Achtman M, Väisänen V, Korhonen TK. Escherichia coli strains binding neuraminyl $\alpha 2-3$ galactosides. Biochem Biophys Res Commun 1983; 111 : 456-461.

19. Moxon ER, Murphy PA. Haemophilus influenzae bacteremia and meningitis resulting from survival of a single organism. Proc Natl Acad Sci USA 1978; 75 : 1534-1536. 